NEW TRENDS IN FLUID MECHANICS RESEARCH

Proceedings of the Fifth International Conference on Fluid Mechanics, Aug.15-19, 2007, Shanghai, China

(C)2007 Tsinghua University Press \& Springer

\title{
3-D Numerical Simulation for Gas-Liquid Two-Phase Flow in Aeration Tank
}

\author{
R. Xue ${ }^{1}$, R. Tian ${ }^{1}$, S. Y. Yan ${ }^{1}$, S. Li ${ }^{2}$ \\ ${ }^{1}$ School of Energy and Power Engineering, Inner Mongolia University of Technology, Hohhot 010051, \\ China \\ ${ }^{2}$ Department of Engineering Mechanics, Tsinghua University, Beijing 100084, China \\ Email: xueruisnow@126.com
}

\begin{abstract}
In the crafts of activated sludge treatment, oxygen supply and the suspending state of activated sludge are primary factors to keep biochemistry process carrying on normally. However, they are all controlled by aeration. So aeration is crucial. The paper focus on aeration, use CFD software to simulate the field of aeration tank which is designed by sludge load method. The main designed size of aeration tank is: total volume: $20000 \mathrm{~m}^{3}$; corridor width: $8 \mathrm{~m}$; total length of corridors: 139m; number of corridors: 3 ; length of one single corridor: $48 \mathrm{~m}$; effective depth: $4.5 \mathrm{~m}$; additional depth: $0.5 \mathrm{~m}$. According to the similarity theory, a geometrical model is set up in proportion of 10:1. The way of liquid flow is submerge to avoid liquid flow out directly. The grid is plotted by dividing the whole computational area into two parts. The bottom part which contains gas pipe and gas exit hole and the above part which is the main area are plotted by tetrahedron and hexahedron respectivelv. In boundary conditions, gas is defined as the primary-phase, and liquid is defined as the secondaryphase. Choosing mixture model, two-phase flow field of aeration tank is simulated by solved the Continuity equation for the mixture, Momentum equation for the mixture, Volume fraction equation for the secondary phases and Relative velocity formula when gas velocity is $10 \mathrm{~m} / \mathrm{s}, 20 \mathrm{~m} / \mathrm{s}, 30 \mathrm{~m} / \mathrm{s}$. what figure shows is the contour of velocity magnitude for the mixture phase when gas velocity is $20 \mathrm{~m} / \mathrm{s}$. Through analysis, the simulation tendency is agreed with actual running of aeration tank. It is feasible to use mixture model to simulate flow field of aeration tank by fluent software. According to the simulation result, the better velocity of liquid or gas (the quantity of inlet air) can be chosen by lower cost, and also the performance of aeration tank can be forecast. It will be helpful for designing and operation.
\end{abstract}

Acknowledgements The support of the sponsorship of National Natural Science Foundation of China (Project No. 50376022) and Inner Mongolia Natural Science Foundation of China (Project No. 200607010701) are gratefully acknowledged.
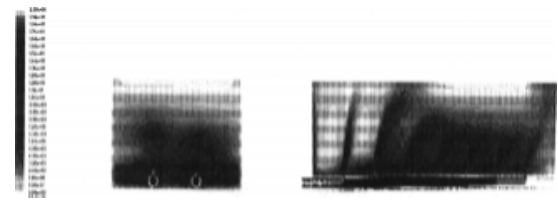

Figure: The contour of velocity magnitude for the mixture phase

\section{REFERENCES}

1. Cheng W, Song C E. Experimental study and numerical model of gas-liquid two-phase flow in aeration tank. Shuili Xuebao, 2001; 12: 32-35

2. Zhang X K, Yao T. CFD analysis on seawater treatment plant for flue gas desulphurization. Power Engineering, 2004; 24(2): 276-279

3. Morchain J, Maranges C. CFD Modeling of a Two-phase Jet Aerator under Influence of a Crossflow. vol.34: Wat.Res. Elsevier Science Ltd., England, 2000 